Article

\title{
New Insight into Phase Transitions of Porous Glass-Based Ferroelectric Nanocomposites
}

\author{
Ewa Rysiakiewicz-Pasek ${ }^{1, *(\mathbb{D}}$, Tatiana Antropova ${ }^{2}$, Irina Polyakova ${ }^{2}$, Olga Pshenko ${ }^{2}$ and \\ Agnieszka Ciżman ${ }^{1}$ \\ 1 Department of Experimental Phyiscs, Wrocław University of Science and Technology, \\ Wyb. Wyspiańskiego 27, 50-370 Wrocław, Poland; Agnieszka.Cizman@pwr.edu.pl \\ 2 Laboratory of the Physical Chemistry of Glass, Grebenshchikov Institute of Silicate Chemistry, \\ Russian Academy of Science, Nab.Makarova 2, 199034 Saint Petersburg, Russia; antr2@yandex.ru (T.A.); \\ ira_pp@list.ru (I.P.); zubanova_oa@mail.ru (O.P.) \\ * Correspondence: Ewa.Rysiakiewicz-Pasek@pwr.edu.pl
}

Received: 17 June 2020; Accepted: 18 August 2020; Published: 21 August 2020

\begin{abstract}
The results of XRD, FTIR and differential scanning calorimetry (DSC) studies of empty porous silica matrices filled with binary mixtures of $\mathrm{K}_{1-\mathrm{x}} \mathrm{Ag}_{\mathrm{x}} \mathrm{NO}_{3}(\mathrm{x}=0.05,0.10)$ are reported in comparison with those obtained for bulk salts in the temperature range of structural phase transitions. Scanning electron microscopic data of the studied empty macroporous and microporous glasses confirmed differences in the pore morphology associated with the presence of silica gel. Accordingly, XRD and FTIR samples contain crystalline phase of $\mathrm{KNO}_{3}$ and $\mathrm{AgNO}_{3}$. The results of calorimetric investigation of porous glasses filled with binary mixtures of $\mathrm{K}_{1-\mathrm{x}} \mathrm{Ag}_{\mathrm{x}} \mathrm{NO}_{3}(\mathrm{x}=0.05,0.10)$ are presented. The results show that in the $\mathrm{K}_{1-\mathrm{x}} \mathrm{Ag}_{\mathrm{x}} \mathrm{NO}_{3}$ nanocomposites, anomalies associated with phase transitions were detected. An influence of the mean value of pores sizes on the ferroelectric phase transition temperatures of $\mathrm{K}_{1-\mathrm{x}} \mathrm{Ag}_{\mathrm{x}} \mathrm{NO}_{3}$ nanocrystals embedded into the porous matrices was determined. The impact of pore space structure on the phase transitions of ferroics nanocomposites was discussed.
\end{abstract}

Keywords: nanocomposites; mixed ferroelectrics; structure; electrical conductivity

\section{Introduction}

Owing to the potentially high dielectric constant and ability to support switchable polarization states and to storing energy, ferroelectric materials are being intensively explored as media for nonvolatile ultra-high-density memories and solar materials. Intense experimental efforts targeted both toward the synthesis of new ferroelectric compounds, as well as the characterization of their physical and materials properties are underway. Molten salt mixtures are in the field of interest of many investigations, owing to their application in chemical industry and energy storage systems [1]. Every bulk $\mathrm{A}_{\mathrm{x}} \mathrm{B}_{1-\mathrm{x}} \mathrm{NO}_{3}$ (where $\mathrm{A}, \mathrm{B}=\mathrm{Li}, \mathrm{Na}, \mathrm{Rb}, \mathrm{K}, \mathrm{Ca}, \mathrm{Cs}, \mathrm{Ag} ; \mathrm{x}=1,0.75,0.5,0.25,0.1,0.05$ ) family member has been extensively studied with respect to interesting physical properties [2-7]. It was shown that confined geometry has an impact on the structural phase transitions including ferroelectric transitions. The studies of ferroelectric nanocomposites are not numerous, while those materials seem very promising. The most investigated salts ferroelectrics within nanopores are sodium and potassium nitrate, mixtures with sodium nitrate [8-14]. The results of the investigations of the physical properties of confinement nitrates have been reported [15-19].

The results of dielectric studies of silicate matrices with cellular pores (37.0 and $26.1 \AA$ in diameter) filled by binary mixtures of $\mathrm{K}_{1-\mathrm{x}} \mathrm{Ag}_{\mathrm{x}} \mathrm{NO}_{3}(\mathrm{x}=0,0.05,0.10)$ have been reported [12,13]. It has been revealed that the permittivity and electrical conductivity increase with increasing $\mathrm{AgNO}_{3}$ concentration 
in bulk samples, as well as with decreasing pore size in the nanocomposites for all values of $\mathrm{x}$. It was also shown that the introduction of small amounts of potassium brings about a noticeable change in the intensity ratio of the elastic Bragg peaks, while leaving the space group characterizing the structure of these nanocomposites unaffected [11]. An increase in the potassium fraction does not result in a substantial decrease in the phase transition point. Measurements of the dielectric response have revealed that an increase in the potassium content gives rise to a marked "hardening" of the lattice in the pre-melting state, which reduces dielectric losses.

The materials such as potassium nitrate $\left(\mathrm{KNO}_{3}\right)$, cesium nitrate $\left(\mathrm{CaNO}_{3}\right)$ and lithium nitrate $\left(\mathrm{LiNO}_{3}\right)$ etc. have been studied in a variety of forms like bulk crystals, opals or thin films in order to use these materials in memory devices operated at low voltage [20-23]. Because of the high coercive field in bulk materials it is necessary to fabricate them in nanoscale for a low voltage operation. The low voltage, the fast switching time and their great efficiency in storing thermal energy make $\mathrm{A}_{\mathrm{x}} \mathrm{B}_{1-\mathrm{x}} \mathrm{NO}_{3}$ nanocomposites promising materials as storage media in large scale integrated access memories (FRAM), switching devices as well as photovoltaic or "rechargeable" batteries. Mixtures of potassium nitrate $\left(\mathrm{KNO}_{3}\right)$ and sodium nitrate $\left(\mathrm{NaNO}_{3}\right)$ are used for storing heat in solar energy installations. This important technological application attracts intense research activity in understanding the properties of the ferroelectric phase in a nanoscale regime. The understanding of the nature of the ferroelectric phase in $\mathrm{A}_{x} \mathrm{~B}_{1-\mathrm{x}} \mathrm{NO}_{3}$, is needed, particularly for the possibility of obtaining a stable ferroelectric or superparaelectric phase at room temperatures $[9,10]$. A determination of the conditions for the photoelectric effect appearance in $\mathrm{A}_{\mathrm{x}} \mathrm{B}_{1-\mathrm{x}} \mathrm{NO}_{3}$-porous glass composites requires detailed studies. Moreover, the materials mixed with a small amount of $\mathrm{AgNO}_{3}$ compound means that the ferroelectric phase becomes more stable and enhances its optoelectronics properties.

Structural investigations indicate that the bulk potassium nitrate $\mathrm{KNO}_{3}$ has the orthorhombic structure Pmnc (phase II) at room temperature [24]. During heating, at temperature $401 \mathrm{~K}$, it transforms to the paraelectric triagonal phase $\mathrm{R}-3 \mathrm{~m}$ (phase I). Upon cooling, $\mathrm{KNO}_{3}$ can change, before returning to phase II, to the ferroelectric triagonal phase with symmetry R-3m (phase III) at the temperature range 397-373 $\mathrm{K}$. The bulk $\mathrm{AgNO}_{3}$ exhibits the orthorhombic structure at room temperature up to $432 \mathrm{~K}$ and undergoes to the rhombohedral above this temperature [25].

A synthesis of $\mathrm{K}_{\mathrm{x}} \mathrm{Ag}_{1-\mathrm{x}} \mathrm{NO}_{3}-\mathrm{PG}$ nanocomposites allows us to obtain novel promising materials with properties desired in electronics (for the ferroelectric random-access memory) and optoelectronics (unconventional photovoltaic materials, radiation detectors). PGs-porous glasses, matrices for ferroelectric nanocomposites, possess a complicated structure. So-called microporous glasses exhibit the mesoporous structure as well as microporous substructure while so-called macroporous glasses represent only mesoporous one. A correlation between glass structures (pores morphology or diameter of pores) and phase transitions is interesting from the scientific and technological point of view.

The aim of this work is to study structure and phase transition of binary salts nanocomposites $\mathrm{K}_{1-x} \mathrm{Ag}_{\mathrm{x}} \mathrm{NO}_{3}$ prepared based on porous glasses. According to our knowledge an investigation of structure and thermal properties of porous matrices embedded by $\mathrm{K}_{1-\mathrm{x}} \mathrm{Ag}_{\mathrm{x}} \mathrm{NO}_{3}$ mixture has not been conducted up to now.

\section{Materials and Methods}

Porous silicate matrices of two types (MIP-microporous and MAP — macroporous ones) in the form of flat-parallel polished plates with a size of $10 \times 10 \times 1 \mathrm{~mm}^{3}$ were obtained as a result of chemical etching of phase-separated sodium borosilicate (SBS) glass of composition (wt.\%): $6.74 \mathrm{Na}_{2} \mathrm{O}$, $20.52 \mathrm{~B}_{2} \mathrm{O}_{3}, 72.59 \mathrm{SiO}_{2}$, and $0.15 \mathrm{Al}_{2} \mathrm{O}_{3}$ [26] in $3 \mathrm{M} \mathrm{HCl}$ solution (glass MIP) and additionally in $0.5 \mathrm{M} \mathrm{KOH}$ solution (glass MAP). To form a two-frame structure, SBS glass was previously subjected to isothermal exposure at $550{ }^{\circ} \mathrm{C}$ for $144 \mathrm{~h}$. Obtained PGs-porous glasses were washed in distilled water and dried at $120^{\circ} \mathrm{C}$ in an air atmosphere. The compositions of PGs and their texture parameters are presented in Table $1[27,28]$. 
Table 1. Composition and the pore structure parameters of MIP and MAP glasses.

\begin{tabular}{|c|c|c|c|c|c|c|c|c|}
\hline \multirow{2}{*}{ Glass } & \multicolumn{5}{|c|}{ Composition, As-Analyzed, wt.\% } & \multirow{2}{*}{$\begin{array}{l}\text { Porosity W, } \\
\mathrm{cm}^{3} / \mathrm{cm}^{3}(\%)\end{array}$} & \multirow{2}{*}{$\begin{array}{l}\text { Specific Surface } \\
\text { Area } S_{A}, \mathrm{~m}^{2} / \mathrm{g}\end{array}$} & \multirow{2}{*}{$\begin{array}{c}\text { Mean Pore } \\
\text { Diameter D, nm }\end{array}$} \\
\hline & $\mathrm{SiO}_{2}$ & $\mathrm{Na}_{2} \mathrm{O}$ & $\mathrm{K}_{2} \mathrm{O}$ & $\mathrm{B}_{2} \mathrm{O}_{3}$ & $\mathrm{Al}_{2} \mathrm{O}_{3}$ & & & \\
\hline MIP & 97.11 & 0.49 & 0 & 2.29 & 0.11 & & 164 & 3 \\
\hline MAP & 94.33 & 0.71 & 0.59 & 4.23 & 0.14 & 0.57 (57) & 87 & 25 \\
\hline
\end{tabular}

According to the existing generally accepted concepts, the so-called secondary silica is formed in the pore space of the MIP glass during the acid leaching of phase-separated alkaline borosilicate glass with interpenetrating coexisting phases. When etching MIP glass in an alkaline solution, secondary silica is dissolved and extracted from the pore space. As a result, the volume porosity and average pore diameter increase, and the specific pore surface decreases.

To obtain composite materials the MIP and MAP matrices were filled by binary mixtures of $\mathrm{K}_{1-\mathrm{x}} \mathrm{Ag}_{\mathrm{x}} \mathrm{NO}_{3}(\mathrm{x}=0.05,0.10)$ from aqueous salt solution at $80^{\circ} \mathrm{C}$. Three-stage impregnation was performed with intermediate and final drying at $120^{\circ} \mathrm{C}$ or $150{ }^{\circ} \mathrm{C}$. As a result the nanocomposite materials PG-MIP05 and PG-MIP1 based on MIP glasses embedded with $\mathrm{K}_{1-\mathrm{x}} \mathrm{Ag}_{\mathrm{x}} \mathrm{NO}_{3}$ for $\mathrm{x}=0.05$ and 0.10 respectively and PG-MAP05 and PG-MAP1 based on MAP glasses for $x=0.05$ and 0.10 were obtained.

Structural measurements were performed using the X-ray Diffraction (XRD, "Bourevestnik" Joint-Stock Company, Saint-Petersburg, Russia) and the Fourier-transform infrared (FTIR, "INFRASPEC" Company, Saint-Petersburg, Russia) spectroscopy methods. The results of electron microscopic examination of the PG matrices accordingly [27] were used. SEM analysis was performed using a Zeiss Merlin field emission scanning electron microscope (Carl Zeiss Merlin FESEM, Oberkochen, Germany) with a GEMINI-II electron optics column, and an oil-free vacuum system. The appliance was equipped with additional devices for X-ray microanalysis Oxford Instruments INCAx-act and the backscattered electron diffraction registration system (EBSD) Oxford Instruments CHANNEL5. XRD studies of the composites were performed by X-ray powder diffraction analysis using the modified DRON-2 device $\left(\mathrm{CuK}_{\alpha}\right.$ radiation; tube voltage $38 \mathrm{kV}$; current $15 \mathrm{~mA}$; the rotation rate of the sample $2 \mathrm{deg} / \mathrm{min}$ ). Phase analysis was carried out by an electronic search engine PCPDFWIN utilizing a powder diffraction database.

FTIR spectroscopy study of the PG MAP matrix and $\mathrm{K}_{1-\mathrm{x}} \mathrm{Ag}_{\mathrm{x}} \mathrm{NO}_{3}$ composites based on it was carried out in the region of $4000-400 \mathrm{~cm}^{-1}$ (with a spectral resolution of $4 \mathrm{~cm}^{-1}$ ) using the technique of pressing the samples into tablets with $\mathrm{KBr}$. The spectra were obtained by the spectrophotometer "SPECORD M-80" (Carl Zeiss Jena, Germany). Processing of the data spectra was performed taking into account the atmosphere spectrum and the spectrum from $\mathrm{KBr}$ followed by smoothing of the spectral features by the FFT Filter method in accordance with the procedure described in Reference [29].

Differential scanning calorimetry (DSC, Metter Toledo, CO, USA) measurements of obtained nanocomposites were performed on a Mettler Toledo DSC- 1 calorimeter at a rate of $2 \mathrm{~K} \mathrm{~min}^{-1}$ under a nitrogen atmosphere with cooling and heating cycles in the temperature range $320-420 \mathrm{~K}$. In the case of porous glasses, samples were additionally annealed in $100^{\circ} \mathrm{C}$ for $2 \mathrm{~h}$ to remove water.

\section{Results and Discussion}

\subsection{Structure Characterization}

SEM image analysis of MAP and MIP porous glasses have shown that PGs have a branched pore system in the nanometer range (see Figure 1). Due to this, PG matrices have excellent adsorption properties, which allow the introduction of useful substances from aqueous salt solutions into their pore space. The differences in the porous space structure of MIP and MAP glasses are associated with the presence of silica gel inside pores of MIP glass and the lack of it in the MAP glass. This is why the 
MIP and MAP glasses have different textural pore structure parameters (Table 1), which should affect the amount of substance introduced and, consequently, the properties of the received composite.
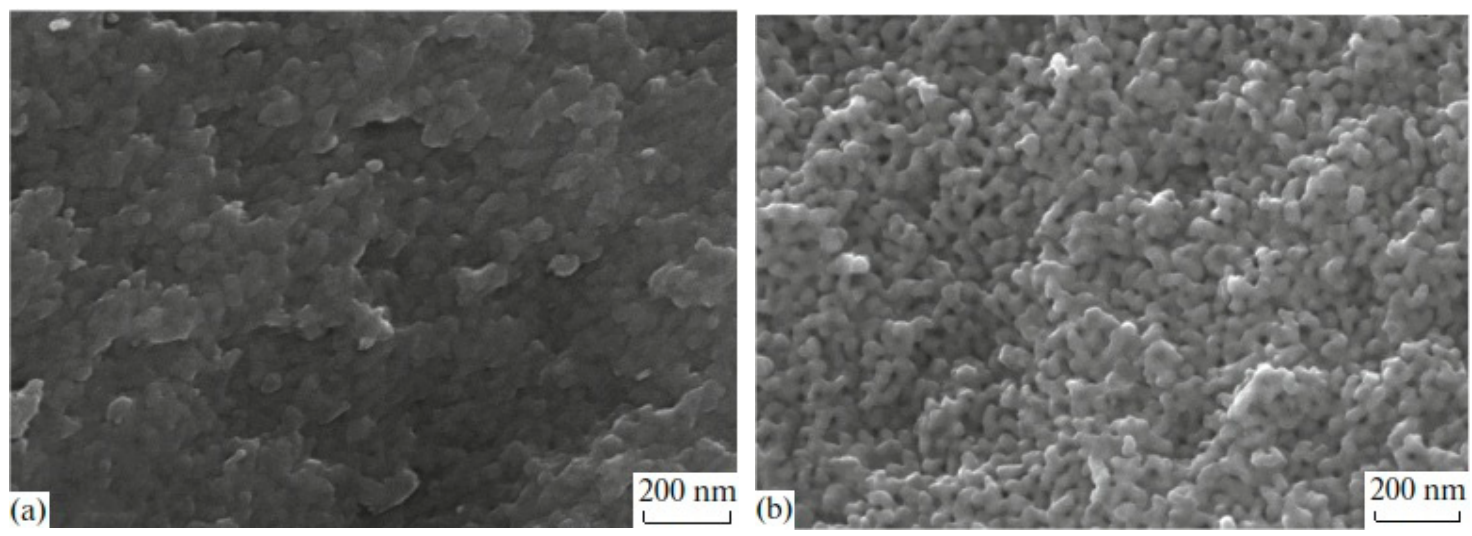

Figure 1. SEM images from cleavages for porous glasses MIP (a) and MAP (b) [27].

As in the case of the introduction of the individual ferroelectrics (for example $\mathrm{KNO}_{3}[30,31]$ ) in the different PG matrices, when using mixed dopants $\left(\mathrm{KNO}_{3}+\mathrm{AgNO}_{3}\right)$ the peaks characteristic of the crystalline phases of the dopants are detected on diffractograms of the composites (Figures 2 and 3 ). Herewith the following influence of the matrix texture parameters (Table 1) is revealed. In the case of thin-pore MIP matrices, only the presence of the crystalline phase of salt, the proportion of which is greater in the mixture (namely, $\mathrm{KNO}_{3}$ ) is detected by the XRD method (Figure 2) and only when shooting from the surface of the sample (data 1 in Figure 2). When using the larger-pored PG MAP matrices, the peaks characteristic of the crystalline phases of both embedded salts $\left(\mathrm{KNO}_{3}\right.$ and $\left.\mathrm{AgNO}_{3}\right)$ are noticed (Figure 3). Judging by these diffractograms taken from the sample surface, the increase in ratio of $\mathrm{KNO}_{3} / \mathrm{AgNO}_{3}$ or $\mathrm{AgNO}_{3} / \mathrm{KNO}_{3}$ salts in the mixed dopant (see Figure 3a or Figure $3 \mathrm{~b}$, respectively) leads to an increase in the intensity of the main peak of salt, the relative proportion of which in the mixture is more. On diffractograms of the sample volume, this effect of the salt ratio is less pronounced. Such a result may be associated with a small amount of the crystalline phase that is beyond the resolution of the used diffractometer.
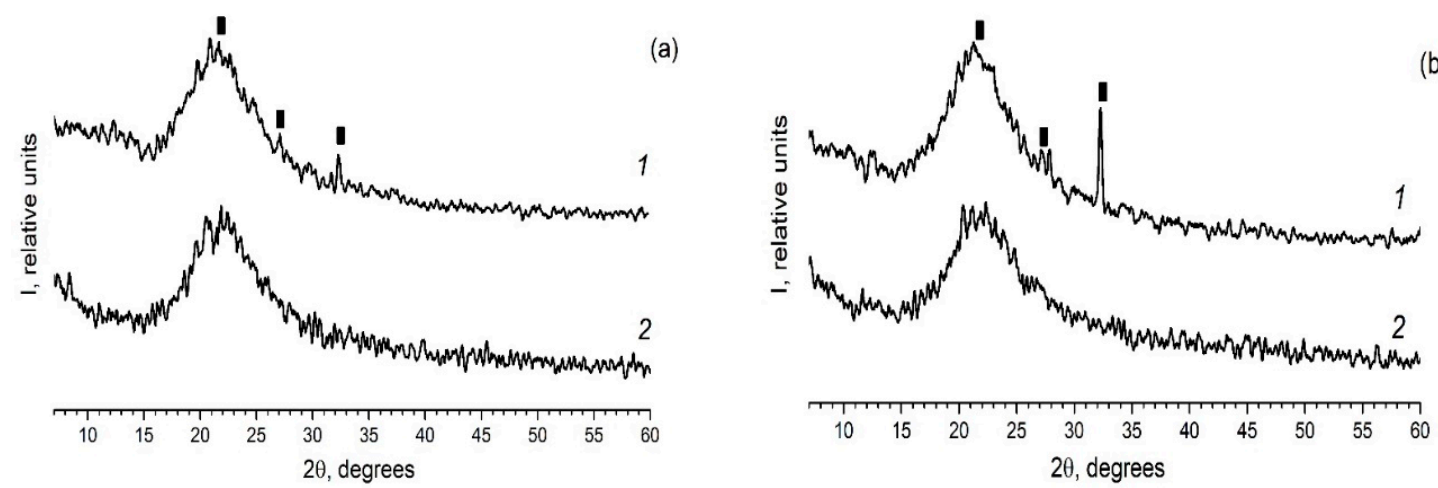

Figure 2. Diffractograms of the composites (a) PG-MIP05 and (b) PG-MIP1. 1-surface of the sample (plate); 2-volume of the sample (i.e., powder). Black rectangular points refer to the crystalline phase $\mathrm{KNO}_{3}(3-482)$. 

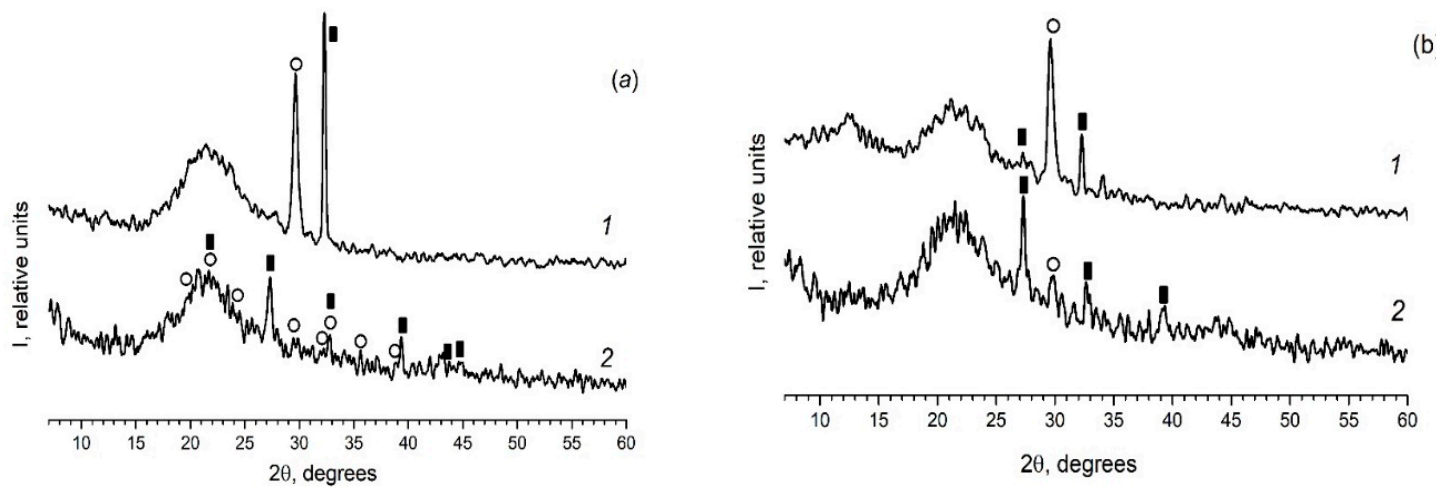

Figure 3. Diffractograms of the composites (a) PG-MAP05 and (b) PG-MAP1. 1-surface of the sample (plate); 2-volume of the sample (i.e., powder). Black rectangular points refer to the crystalline phase $\mathrm{KNO}_{3}$ (3-482), open circle points mark the crystalline phase $\mathrm{AgNO}_{3}$ (74-2076).

The IR spectra for PG-MAP-empty porous matrix and composites (PG-MAP05 and PG-MAP1) are presented in Figure 4.

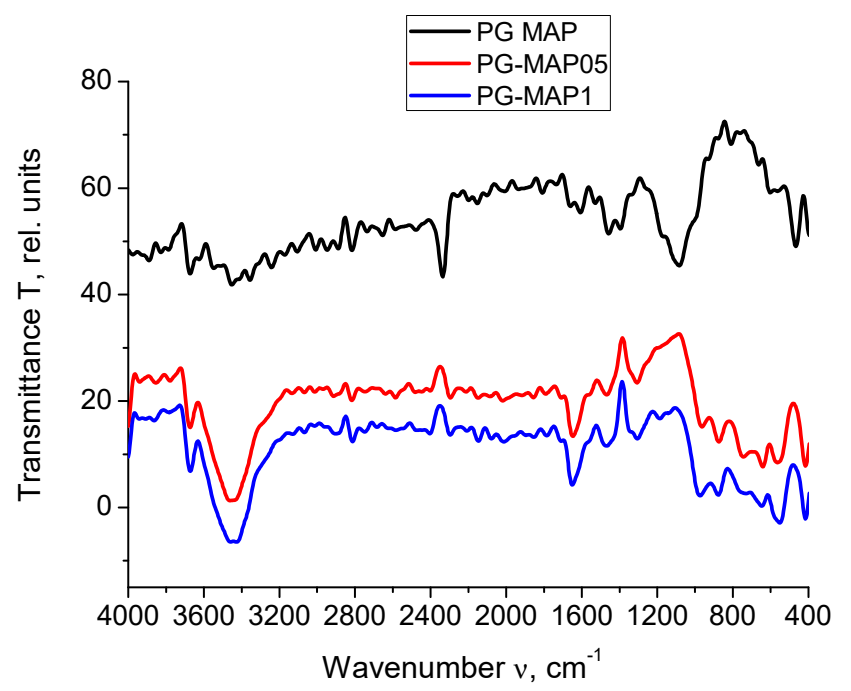

(a)

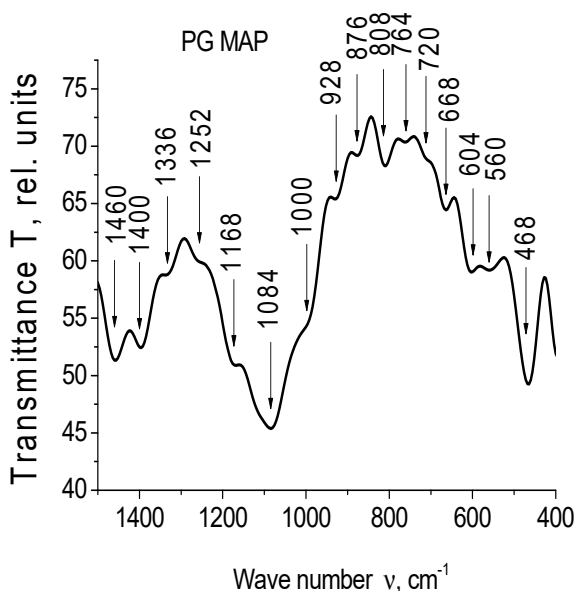

(b)

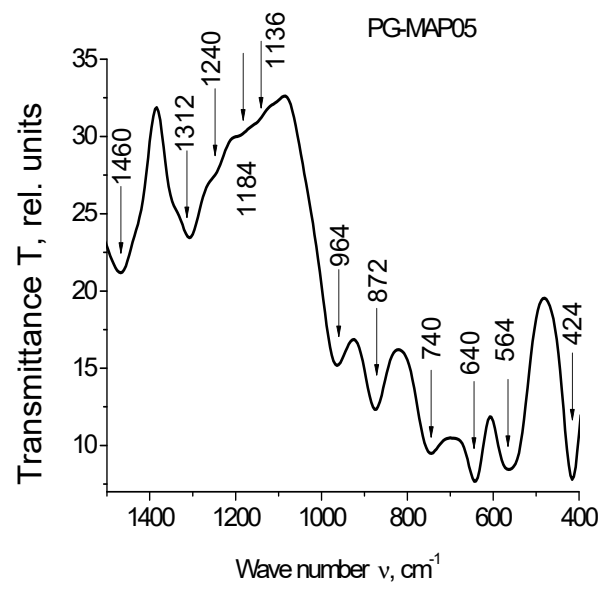

(c)

Figure 4. Cont. 


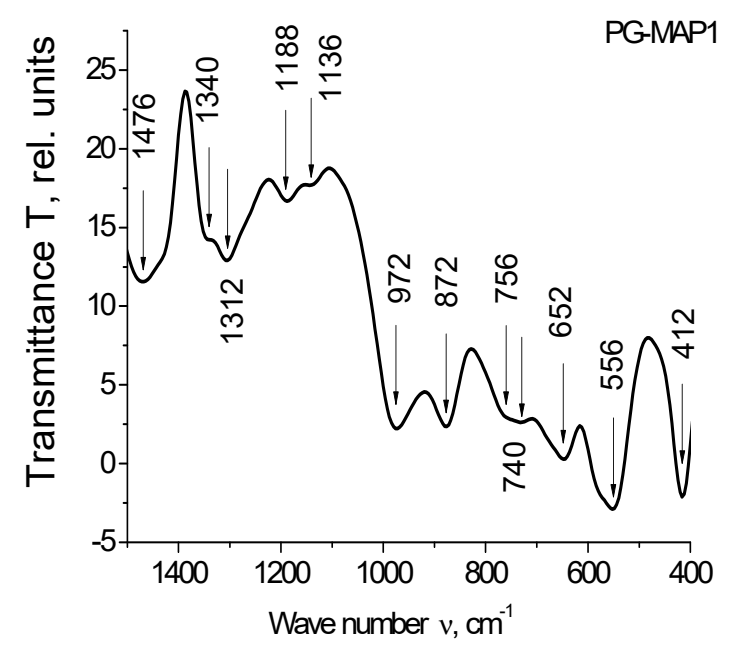

(d)

Figure 4. IR spectra of the PG-matrix (PG MAP) and composites (PG-MAP05 and PG-MAP1) in the spectral range (a) (4000-400) $\mathrm{cm}^{-1}$, (b-d) (1500-400) $\mathrm{cm}^{-1}$.

It is seen that the IR spectra of the base matrix (PG-MAP) and of the composites (PG-MAP05 and PG-MAP1) based on it have both similar and different absorption bands. In the case of similar bands, their shift and different intensity can be observed, but the characteristic spectral ranges remain.

According to the literature (see overviews in [32-34]) absorption bands in the spectral ranges $3672-3248 \mathrm{~cm}^{-1}$ and $2816-2016 \mathrm{~cm}^{-1}$ are due to the presence of hydroxyl groups and water in the samples. The bands in the range $1568-1136 \mathrm{~cm}^{-1}$ correspond to the vibrations of bonds $(\mathrm{B}-\mathrm{O})$ in different boron-oxygen structural groups ( $\left[\mathrm{BO}_{3 / 2}\right],\left[\mathrm{BO}_{4 / 2}\right]$, etc.). Bands in the ranges $1084-668 \mathrm{~cm}^{-1}$ and $564-412 \mathrm{~cm}^{-1}$ correspond to vibrations of the ( $\left.\mathrm{Si}-\mathrm{O}-\mathrm{Si}\right)$ bridges and tetrahedra $\left[\mathrm{SiO}_{4 / 2}\right]$.

Bands at $740 \mathrm{~cm}^{-1}$, as well as at $652 \mathrm{~cm}^{-1}$ and $640 \mathrm{~cm}^{-1}$ are associated with the presence of silver $[35,36]$. The bands in the range $424-412 \mathrm{~cm}^{-1}$ correspond to vibrations of the (K-O) bonds [37].

It should be noted that the bands at $1340 / 1312 \mathrm{~cm}^{-1}$ and $740 \mathrm{~cm}^{-1}$ can be attributed to $\mathrm{AgNO}_{3}$ (1348 $\mathrm{cm}^{-1}$ and $733 \mathrm{~cm}^{-1}$ respectively according to [38]). At the same time, taking into account the possible shift, the band at $1340 \mathrm{~cm}^{-1}$ can be attributed to $\mathrm{KNO}_{3}\left(1380 \mathrm{~cm}^{-1}\right.$ according to [38]).

The band at $872 \mathrm{~cm}^{-1}$ (taking into account the possible shift) may indicate the presence of both $\mathrm{AgNO}_{3}$ and $\mathrm{KNO}_{3}\left(835 \mathrm{~cm}^{-1}\right.$ and $824 \mathrm{~cm}^{-1}$, respectively, according to [38]). The band $1480-1476 \mathrm{~cm}^{-1}$ is associated with the presence of anions $\mathrm{NO}_{3}{ }^{-}$[39].

\subsection{Differential Scanning Calorimetry (DSC)}

Differential scanning calorimetry (DSC) was used to determine the solid state phase transitions of the salt $\mathrm{K}_{1-\mathrm{x}} \mathrm{Ag}_{\mathrm{x}} \mathrm{NO}_{3}$ mixture. In order to improve the temperature resolution of measurements to record the heat flow curve as a function of temperature, a low scanning rate was chosen.

Figures 5 and 6 depict the heat flow of bulk and nanocomposites (MIP and MAP) with binary $\mathrm{K}_{1-\mathrm{x}} \mathrm{Ag}_{\mathrm{x}} \mathrm{NO}_{3}(\mathrm{x}=0.05$ and $\mathrm{x}=0.10)$ mixtures vs. temperature. As can been seen (Figures $5 \mathrm{~b}$ and $6 \mathrm{~b}$ ) for the bulk binary $\mathrm{K}_{1-\mathrm{x}} \mathrm{Ag}_{\mathrm{x}} \mathrm{NO}_{3}$ system during the heating, the anomaly related to the phase transition from II-I phase transition in $\mathrm{KNO}_{3}$, is observed at $404 \mathrm{~K}$ and $407 \mathrm{~K}$ for $\mathrm{x}=0.05$ and 0.10 , respectively. An additional anomaly at $413 \mathrm{~K}$ can be related to $\alpha \rightarrow \beta$ transformation in $\mathrm{AgKNO}_{3}$. Investigation of the phase transition in binary bulk $\mathrm{K}_{1-\mathrm{x}} \mathrm{Ag}_{\mathrm{x}} \mathrm{NO}_{3}$ for $\mathrm{x}<0,4$ has been previously performed [40,41]. According to Meszaros Szecesenyi et al. [40] $\mathrm{AgNO}_{3}$ undergoes an $\alpha \rightarrow \beta$ transformation at $432 \mathrm{~K}$ for silver nitrate-rich region. Upon the heating phase transitions for composites $\mathrm{K}_{1-\mathrm{x}} \mathrm{Ag}_{\mathrm{x}} \mathrm{NO}_{3}$ based on MAP glasses appear at $402 \mathrm{~K}$ for $\mathrm{x}=0.05$ and $404 \mathrm{~K}$ for $\mathrm{x}=0.10$ (Figures $5 \mathrm{a}$ and 6a). Probably it is connected with presence of $\mathrm{KNO}_{3}$ inside the pores and associated with the phase transition between 
the phase II and I in the potassium nitrate. The anomaly associated with silver nitrate transformation is invisible.

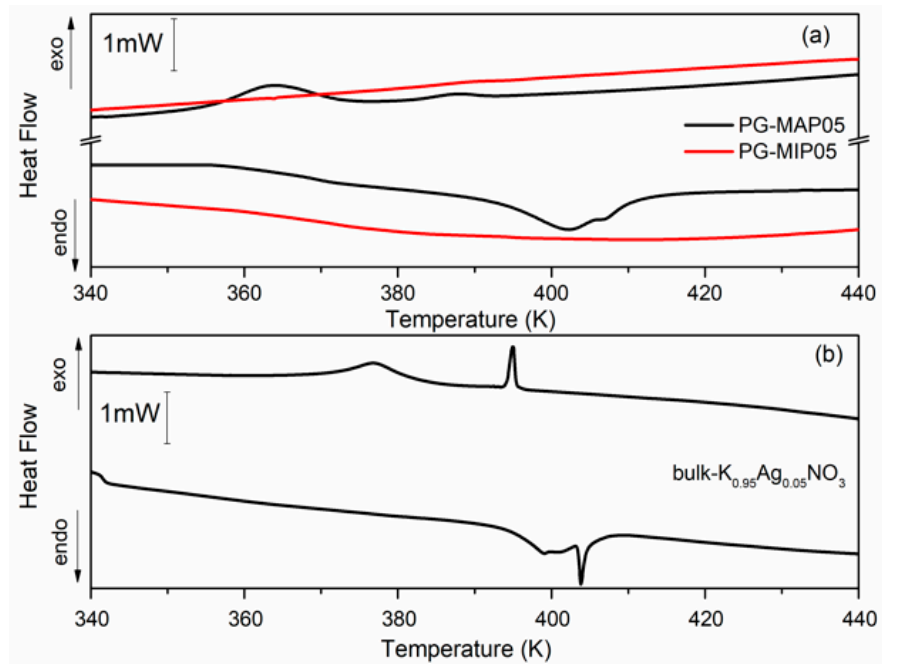

Figure 5. Differential scanning calorimetry (DSC) traces for (a) PG-MAP05 and PG-MIP05 nanocomposites and for $(\mathbf{b})$ bulk $\mathrm{K}_{0.95} \mathrm{Ag}_{0.05} \mathrm{NO}_{3}$ during the cooling and heating scans (rate: $2 \mathrm{~K} \mathrm{~min}^{-1}$ ).
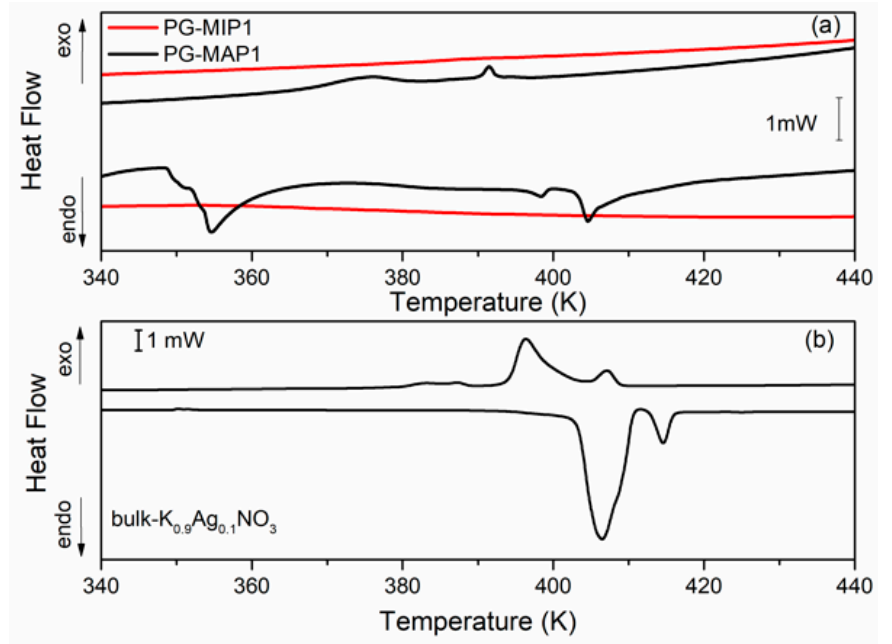

Figure 6. DSC traces for (a) PG-MAP1 and PG-MIP1 nanocomposites and for (b) bulk $\mathrm{K}_{0.90} \mathrm{Ag}_{0.10} \mathrm{NO}_{3}$ during the cooling and heating scans (rate: $2 \mathrm{~K} \mathrm{~min}^{-1}$ ).

During the cooling cycle for bulk binary systems with $\mathrm{x}=0.05$, two anomalies at $376 \mathrm{~K}$ and $395 \mathrm{~K}$ are revealed. Two anomalies also appear for the bulk binary system with $\mathrm{x}=0.10$ at $385 \mathrm{~K}$ and $397 \mathrm{~K}$ (Figures $5 \mathrm{~b}$ and $6 \mathrm{~b}$ ). These anomalies can be assigned to the I-III and III-II phases seen in $\mathrm{KNO}_{3}$ bulk crystals. Similar results were obtained by Meszaros Szecesenyi [40] where the DSC anomaly assigned to the I-III phase transformation in bulk $\mathrm{K}_{1-\mathrm{x}} \mathrm{Ag}_{\mathrm{x}} \mathrm{NO}_{3}$ with different $\mathrm{AgNO}_{3}$ amount was observed. The third anomaly observed for the bulk binary system with $\mathrm{x}=0.10$ can be related to the phase transition in $\mathrm{AgNO}_{3}$. The anomalies connected with the phase transition between phase I to III and from III to II in $\mathrm{KNO}_{3}$ for MAP glasses embedded with $\mathrm{K}_{1-\mathrm{x}} \mathrm{Ag}_{\mathrm{x}} \mathrm{NO}_{3}$ occur at $364-389 \mathrm{~K}$ for $\mathrm{x}=0.05$ and $375-392 \mathrm{~K}$ for $\mathrm{x}=0.10$ (Figures $5 \mathrm{a}$ and $6 \mathrm{a}$ ). These phase transition temperatures are lower than in the bulk $\mathrm{KNO}_{3}$. The observed tendency of changes of phase transition temperatures in composite materials in comparison with the bulk potassium nitrate is similar to those presented in our previous work [42] and is associated with the size effect. It was seen that for MAP nanocomposites with lower concentrations of silver nitrate the anomalies of heat flow are more smeared. In both MAP05 and 
MAP1, the observed broadening of phase transitions anomalies can be attributed to the slowing down of the phase transition in restricted geometry [42].

As mentioned earlier, the anomalies associated with phase transition in binary systems have been observed only for MAP nanocomposites, while for MIP binary nanocomposites (Figures 5a and 6a) no visible changes of the specific heat, associated with phase transition, were observed. The absence of a clear maximum on temperatures dependent on the specific heat of MIP nanocomposites may be caused by the presence of silica gel (so-called secondary silica) inside pores of dielectric matrix, which leads to a decrease in the size of the pores that are determined by the size of the gaps between the globules of secondary silica, and have prevented the introduction of the nitrate. According to XRD data, the crystalline phase of $\mathrm{KNO}_{3}$ in composites based on PG MIP matrices is detected only in the surface layer of samples (Figure 2, dependencies 1) with extremely low intensity. Judging by the diffractograms of the crushed samples, they are absent or amorphous in volume (Figure 2, dependencies 2), which may be due to a small pore size which does not favor the ferroelectric materials introducing process and thus can determine the critical size of the investigated binary system.

\section{Conclusions}

We report the synthesis, structural properties and phase transitions of $\mathrm{K}_{1-\mathrm{x}} \mathrm{Ag}_{\mathrm{x}} \mathrm{NO}_{3}$ porous glasses-based nanocomposites. Based on the results of X-ray diffraction we can conclude that the existence of silica gel inside pores has an impact on porous glass morphology, porosity, specific surface area, and mean diameter of pores. It has been revealed that the intensity of the crystalline phase of $\mathrm{KNO}_{3}$ depends on pore size and total ration of $\mathrm{KNO}_{3} / \mathrm{AgNO}_{3}$ in impregnation solution. The influence of $\mathrm{AgNO}_{3}(\mathrm{x}=0.05$ or $\mathrm{x}=0.10)$ content in binary mixtures of $\mathrm{K}_{1-\mathrm{x}} \mathrm{Ag}_{\mathrm{x}} \mathrm{NO}_{3}$ on phase transition temperature and the shape of the curve for nanocomposites based on microporous (MIP) and macroporous (MAP) matrices has been observed. It is seen that the structure of pores (MIP or $\mathrm{MAP}$ ) determines phase transition temperature and the shape of the curve at the same $x$ content.

Author Contributions: Conceptualization: T.A., E.R.-P. and A.C.; methodology: T.A., A.C. and E.R.-P.; formal analysis: T.A., E.R.-P.; investigation: I.P., O.P. and A.C.; data curation: A.C., O.P. I.P.; writing-original draft preparation: T.A., E.R.-P. and A.C.; writing-review and editing: T.A., E.R.-P. and A.C.; visualization: A.C., E.R.-P. All authors have read and agreed to the published version of the manuscript.

Funding: This research received no external funding.

Acknowledgments: The work was carried out under the Polish-Russian joint research project "Special phase-separated, porous glasses and new nano-composite materials with useful functional properties on their basis" (2017/2019). A.C. and E.R.-P. thank Wroclaw University of Science and Technology for financial support. T.A., O.P. and I.P. thank Grebenshchikov Institute of Silicate Chemistry RAS for financial support (State Assignment; project 0097-2019-0015). Authors thank to M.A. Girsova and G.F. Golovina for measuring FTIR spectra of the composites.

Conflicts of Interest: The authors declare no conflict of interest.

\section{References}

1. Federsel, K.; Wortmann, J.; Ladenberger, M. High-temperature and Corrosion Behavior of Nitrate Nitrite Molten Salt Mixtures Regarding their Application in Concentrating Solar Power Plants. Energy Procedia 2015, 69, 618-625. [CrossRef]

2. Kutnjak, Z.; Vodopivec, B.; Blinc, R.; Fokin, A.V.; Kumzerov, Y.A.; Vakhrushev, S.B. Calorimetric and dielectric studies of ferroelectric sodium nitrite confined in a nanoscale porous glass matrix. J. Chem. Phys. 2005, 123, 084708. [CrossRef] [PubMed]

3. Nabereznov, A.; Fokin, A.; Kumzerov, Y.; Sobotnikov, A.; Vakhrushev, S.; Dorner, B. Structure and properties of confined sodium nitrite. Eur. Phys. J. E 2003, 12, 21-24. [CrossRef] [PubMed]

4. Bury, P.C.; McLaren, A.C. Pyroelectric Properties of Rubidium, Cesium, and Thallium Nitrates. Phys. Stat. Solidi 1969, 31, 799-806. [CrossRef]

5. Sawada, S.; Nomura, S.; Fujii, S. Ferroelectricity in the Phase III of $\mathrm{KNO}_{3}$. J. Phys. Soc. Jpn. 1958, 13, 1549. [CrossRef] 
6. Myasnikova, T.P.; Evseeva, R.Y. Infrared spectra of $\mathrm{KNO}_{3}$ and $\mathrm{NaNO}_{2}$ at phase transitions. Sov. Phys. J. 1970, 13, 773-775. [CrossRef]

7. Asao, Y.; Yoshida, I.; Ando, R.; Sawada, S. The Electrical Resistivities of $\mathrm{NaNO}_{2}$ and $\mathrm{KNO}_{3}$ Crystals. J. Phys. Soc. Jpn. 1962, 17, 442-446. [CrossRef]

8. Godfrey, R.B.; Scott, J.F.; Meadows, H.B.; Golabi, M.; Araujo, C.A.; McMillan, L.D. Analysis of electrical switching in sub-micron $\mathrm{KNO}_{3}$ thin films. Ferroelectr. Lett. Sect. 1986, 5, 167-172. [CrossRef]

9. Vera-Avila, L.E.; Garcia-Salgado, E.; Garcia de Liasera, M.P.; Pena-Alvarez, A. Binding Characteristics of Bovine Serum Albumin Encapsulated in Sol-Gel Glasses: An Alternative for Protein Interaction Studies. Anal. Biochem. 2008, 373, 272-280. [CrossRef]

10. Pankova, S.V.; Poborchii, V.V.; Solov'ev, V.G. The giant dielectric constant of opal containing sodium nitrate nanoparticles. J. Phys. Condens. Matter 1996, 8, L203-L206. [CrossRef]

11. Vakhrushev, S.B.; Kumzerov, Y.A.; Fokin, A.; Naberezhnov, A.A.; Zalar, B.; Lebar, A.; Blinc, R. ${ }^{23}$ Na spin-lattice relaxation of sodium nitrite in confined geometry. Phys. Rev. B 2004, 70. [CrossRef]

12. Tien, C.; Charnaya, E.V.; Lee, M.K.; Baryshnikov, S.V.; Sun, S.Y.; Michel, D.; Вцhlmann, W. Coexistence of melted and ferroelectric states in sodium nitrite within mesoporous sieves. Phys. Rev. B 2005, 72, 104105. [CrossRef]

13. Tien, C.; Charnaya, E.V.; Lee, M.K.; Baryshnikov, S.V.; Michel, D.; Bцhlmann, W. NMR studies of structure and ferroelectricity for Rochelle salt nanoparticles embedded in mesoporous sieves. J. Phys. Condens. Matter 2008, 20, 215205. [CrossRef]

14. Vakhrushev, S.B.; Golosovsky, I.V.; Koroleva, E.Y.; Naberezhnov, A.A.; Okuneva, N.M.; Smirnov, O.P.; Fokin, A.V.; Tovar, M.; Glazman, M. Structure and dielectric response of $\mathrm{Na}_{1-x} \mathrm{~K}_{x} \mathrm{NO}_{2}$ nanocomposite solid solutions. Phys. Solid State 2008, 50, 1548-1554. [CrossRef]

15. Awschalom, D.D.; Warnock, J. Super cooled liquids and solids in porous glass. Phys. Rev. B 1987, 35, 6779-6785. [CrossRef]

16. Brown, D.W.; Sokol, P.E.; Ehrlich, S.N. New disorder induced phase transitions of classical rare gases in porous vycor glass. Phys. Rev. Lett. 1998, 81, 1019-1022. [CrossRef]

17. $\mathrm{Mu}, \mathrm{R} . ;$ Malhotra, V.M. Effects of surface and physical confinement on the phase transitions of cyclohexane in porous silica. Phys. Rev. B 1991, 44, 4296-4303. [CrossRef]

18. Charnaya, E.V.; Tien, C.; Lin, K.J.; Kumzerov, Y.A. X-ray and resistance studies of the melting and freezing phase transitions for gallium in an opal. J. Phys. Condens. Matter 1998, 10, 7273-7282. [CrossRef]

19. Poprawski, R.; Rysiakiewicz-Pasek, E.; Sieradzki, A.; Ciżman, A.; Polańska, J. Ferroelectric phase transitions in $\mathrm{KNO}_{3}$ embedded into porous glasses. J. NonCryst. Solids 2007, 353, 4457-4461. [CrossRef]

20. Jia, W.; Fan, C.; Wang, L.; Wang, Q.; Zhao, M.; Zhou, A.; Li, J. Extremely Accessible Potassium Nitrate (KNO3) as the Highly Efficient Electrolyte Additive in Lithium Battery. ACS Appl. Mater. Interfaces 2016, 8, 15399-15405. [CrossRef]

21. Fernández, A.G.; Gomez-Vidal, J.C. Thermophysical properties of low cost lithium nitrate salts produced in northern Chile for thermal energy storage. Renew. Energy 2017, 101, 120-125. [CrossRef]

22. Fernándeza, A.G.; Ushakb, S.; Galleguillosb, H.; Péreza, F.J. Development of new molten salts with LiNO3 and $\mathrm{Ca}(\mathrm{NO} 3) 2$ for energy storage in CSP plants. Appl. Energy 2014, 119, 131-140. [CrossRef]

23. Rogeta, F.; Favotto, C.; Rogez, J. Study of the $\mathrm{KNO}_{3}-\mathrm{LiNO}_{3}$ and $\mathrm{KNO}_{3}-\mathrm{NaNO}_{3}-\mathrm{LiNO}_{3}$ eutectics as phase change materials for thermal storage in a low-temperature solar power plant. Sol. Energy 2013, 95, 155-169. [CrossRef]

24. Nimmo, J.K.; Lucas, B.W. The crystal structures of $\gamma$ and $\beta \mathrm{KNO}_{3}$ and the $\alpha \leftarrow \gamma \leftarrow \beta$ phase transformations. Acta Cryst. Sect. B 1976, 32, 1968-1971. [CrossRef]

25. Fraser, W.L.; Kennedy, S.W.; Taylor, G.F. Structural relationships between the polymorphs of silver nitrate. Acta Cryst. Sect. B 1977, 33, 311-313. [CrossRef]

26. Antropova, T.V.; Girsova, M.A.; Anfimova, I.N.; Drozdova, I.A. Spectral properties of the high-silica porous glasses doped by silver halides. J. Lumin. 2018, 193, 29-33. [CrossRef]

27. Ermakova, L.E.; Volkova, A.V.; Kuznetsova, A.S.; Grinkevich, E.A.; Antropova, T.V. Electrokinetic Characteristics of Porous Glasses in Solution of Sodium and Iron (III) Chlorides. Colloid J. 2018, 80, 255-265. [CrossRef]

28. Kuznetsova, A.S.; Ermakova, L.E.; Anfimova, I.N.; Antropova, T.V. Electrokinetic characteristics of bismuth-containing materials based on porous glasses. Glass Phys. Chem. 2020, 46, 290-297. 
29. Pshenko, O.A.; Girsova, M.A.; Golovina, G.F.; Antopova, T.V. Study of the Iron-Containing Sodium Borosilicate Two-Phase Classes and Porous Glasses by Optical Spectroscopy. Glass Phys. Chem. 2016, 42, 33-37. [CrossRef]

30. Lapshin, E.A.; Arsentev, M.Y.; Pshenko, O.A.; Antropova, T.V. Structure of the ferroelectric phase $\mathrm{KNO}_{3}$, formed in nanoporous glass matrix. Fiz. Khim. Stekla 2012, 38, 817-819. (In Russian)

31. Pshenko, O.A.; Antropova, T.V.; Arsentev, M.Y.; Drozdova, I. New vitreous nanocomposites containing phases of $\mathrm{Fe}_{3} \mathrm{O}_{4}$ and $\gamma-\mathrm{KNO}_{3}$. Glass Phys. Chem. 2015, 41, 509-514. [CrossRef]

32. Girsova, M.A.; Golovina, G.F.; Anfimova, I.N.; Kurilenko, L.N. Infrared Spectroscopy Study of Silver-Containing Composite Materials Based on Nanoporous Silicate Glass Doped with $\mathrm{Tb}^{3+}$ or Sm ${ }^{3+}$ Ions. Glass Phys. Chem. 2019, 45, 325-331. [CrossRef]

33. Girsova, M.A.; Golovina, G.F.; Kurilenko, L.N.; Antropova, T.V. Synthesis and study of bismuth-containing high-silica glass by the IR spectroscopy method. Glass Phys. Chem. 2015, 41, 93-97. [CrossRef]

34. Girsova, M.A.; Golovina, G.F.; Drozdova, I.A.; Polyakova, I.G.; Antropova, T.V. Infrared studies and spectral properties of photochromic high silica glasses. Opt. Appl. 2014, 44, 337-344.

35. Burns, A.E.; Royle, M.; Martin, S.W. Infrared spectroscopy of AgI doped $\mathrm{Ag}_{2} \mathrm{~S}+\mathrm{B}_{2} \mathrm{~S}_{3}$ fast ion conducting thioborate glasses. J. NonCryst. Solids 2000, 262, 252-257. [CrossRef]

36. Waterhouse, G.I.N.; Bowmaker, G.A.; Metson, J.B. The thermal decomposition of silver (I, III) oxide: A combined XRD, FT-IR and Raman spectroscopic study. Phys. Chem. Chem. Phys. 2001, 3, 3838-3845. [CrossRef]

37. Samee, M.A.; Edukondalu, A.; Ahmmad, S.K.; Taqiullah, S.M.; Rahman, S. Mixed-Alkali Effect in $\mathrm{Li}_{2} \mathrm{O}-\mathrm{Na}_{2} \mathrm{O}-\mathrm{K}_{2} \mathrm{O}-\mathrm{B}_{2} \mathrm{O}_{3}$ Glasses: Infrared and Optical Absorption Studies. J. Electron. Mater. 2013, 42, 2516-2524. [CrossRef]

38. Miller, F.A.; Wilkins, C.H. Infrared spectra and characteristic frequencies of inorganic ions. Anal. Chem. 1952, 24, 1253-1294. [CrossRef]

39. Coelho, J.; Nandyalam, S.H.; Gomes, P.S.; Sampaio, P.; Pacheco, A.P.; Nunes, O.C.; Lopes, M.A.; Fernandes, M.H.; Santos, J.D. Development and Characterization of $\mathrm{Ag}_{2} \mathrm{O}$-Doped $\mathrm{ZnLB}$ Glasses and Biological Assessment of $\mathrm{Ag}_{2} \mathrm{O}-\mathrm{ZnLB}-\mathrm{Hydroxyapatite} \mathrm{Composites.} \mathrm{J.} \mathrm{Am.} \mathrm{Ceram.} \mathrm{Soc.} \mathrm{2012,} \mathrm{95,} \mathrm{2732-2740.}$ [CrossRef]

40. Mgszaros Szecsenyi, K.; Tomor, K.; Pokol, G. The phase diagram of the $\mathrm{AgNO}_{3}-\mathrm{KNO}_{3}$ System Determined by Differential Scanning Calorimetry. J. Therm. Anal. 1994, 41, 125-134. [CrossRef]

41. Boa, D.; Hellali, D.; Licbarski, D.; Tizzotti, M.; Zamali, H.; Favotto, C.; Benigni, P.; Rogez, J. Experimental investigation and calculation of the binary $\left(\mathrm{AgNO}_{3}+\mathrm{KNO}_{3}\right)$ phase diagram. J. Chem. Thermodyn. 2015, 81, 44-51. [CrossRef]

42. Sieradzki, A.; Komar, J.; Rysiakiewicz-Pasek, E.; Ciżman, A.; Poprawski, R. Calorimetric Investigations of Phase Transitions in $\mathrm{KNO}_{3}$ Embedded into Porous Glasses. Ferroelectrics 2010, 402, 60-65. [CrossRef] 